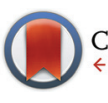

CrossMark \&lick for updates

Cite this: Polym. Chem., 2015, 6 , 4605

Received 24th March 2015, Accepted 6th May 2015

DOI: $10.1039 / \mathrm{c} 5 \mathrm{py} 00435 \mathrm{~g}$

www.rsc.org/polymers

\section{A dinuclear gold(I) complex as a novel photoredox catalyst for light-induced atom transfer radical polymerization $\uparrow$}

\author{
Frida Nzulu, ${ }^{a}$ Sofia Telitel, ${ }^{b}$ François Stoffelbach, ${ }^{a}$ Bernadette Graff, ${ }^{b}$ \\ Fabrice Morlet-Savary, ${ }^{\mathrm{b}}$ Jacques Lalevée, ${ }^{\text {b }}$ Louis Fensterbank, ${ }^{* a}$ \\ Jean-Philippe Goddard ${ }^{* c}$ and Cyril Ollivier ${ }^{\star a}$
}

\begin{abstract}
Controlled/living atom transfer radical polymerization of methacrylates and acrylates initiated by ethyl $\alpha$-bromophenylacetate (EBPA) as the initiator in the presence of low loadings ( $1.25 \mathrm{~mol} \% \mathrm{vs}$. initiator) of a dinuclear gold(I) complex based photocatalyst $\left[\mathrm{Au}_{2}(\mu-\mathrm{dppm})_{2}\right] \mathrm{Cl}_{2}$ has been accomplished in solution and in laminate under UVA and visible-light photoreductive conditions. In solution, the linear increase of molecular weights with methyl methacrylate (MMA) conversion and the low dispersity are consistent with a controlled/living process. In a film, trimethylolpropane triacrylate (TMPTA) was polymerized and the ethyl $\alpha$-bromophenylacetate $(E B P A) /\left[\mathrm{Au}_{2}(\mu-\mathrm{dppm})_{2}\right] \mathrm{Cl}_{2}$ system resulted in a faster rate of polymerization compared to EBPA/Ir(ppy $)_{3}$. Chain extensions of polymers were successfully conducted leading to block copolymers, which also confirms the living character of this new system. Photophysical experiments support a conventional photoredox-catalyzed ATRP mechanism. Finally, this approach utilizes a gold catalyst featuring better solubility and lower cost than the well-known $\operatorname{Ir}(\mathrm{ppy})_{3}$ complex.
\end{abstract}

\section{Introduction}

Controlled/living radical polymerization (CRP) is among the most rapidly developing areas of chemistry and polymer science. Over the last few decades, many novel previously inaccessible materials have been prepared using CRP. This process has provided access to nearly all types of macromolecular species exhibiting predetermined molecular weights, low dispersities, and precisely controlled composition and architectures (block copolymers, star-like, comb-like, dendritic etc.). ${ }^{1}$ The CRP techniques that have been implemented so far consist mainly of reversible addition-fragmentation chain transfer polymerization (RAFT) ${ }^{2}$ organometallic radical

\footnotetext{
${ }^{a}$ UMR CNRS 8232, Institut Parisien de Chimie Moléculaire, Sorbonne Université UPMC Univ Paris 06, 4 place Jussieu, CC 229, F-75252 Paris Cedex 05, France. E-mail: louis.fensterbank@upmc.fr, cyril.ollivier@upmc.fr

${ }^{b}$ Institut de Science des Matériaux de Mulhouse IS2M, UMR 7361 CNRS, Université de Haute Alsace, 15 Rue Jean Starcky, 68057 Mulhouse Cedex, France.

E-mail: jacques.lalevee@uha.fr

${ }^{c}$ Laboratoire de Chimie Organique et Bioorganique EA 4566, Université de HauteAlsace, Ecole Nationale Supérieure de Chimie de Mulhouse, 3 bis rue Alfred Werner, 68093 Mulhouse Cedex, France.E-mail: jean-philippe.goddard@uha.fr

$\dagger$ Electronic supplementary information (ESI) available: Characterization data of the catalyst, organic compounds and polymers are provided. Photochemical and photophysical properties of the catalytic system are available. See DOI: 10.1039/ c5py00435g
}

polymerization, ${ }^{3}$ nitroxide-mediated polymerization $(\mathrm{NMP})^{4}$ and atom transfer radical polymerization (ATRP). ${ }^{5}$ In all these CRP methods, control is achieved by the equilibrium maintained between an active and a dormant chain via a reversible deactivation mechanism (RDRP). Currently, these systems are initiated by free-radical initiators and/or metal catalysts and by external stimuli including chemical reducing agents, microwave, heat, electrical current and light. ${ }^{6}$

The use of photochemical stimuli had a tremendous impact not only in organic chemistry, ${ }^{7}$ molecular biology and electronics but also in polymer chemistry since the pioneer work of Otsu. ${ }^{8}$ Accordingly some controlled radical photopolymerization (CRP2) methodologies have been recently proposed. The most substantial advantage is that photo-induced processes are extremely fast, and give access to spatially controlled reactions for photografting, photoinduced modification or (micro)patterning of surfaces. They also represent an environmentally friendly alternative to thermal processes allowing reactions to proceed under mild conditions and to use functional groups and materials that decompose at high temperatures. Several CRP2 systems including transition metal-mediated CRP, ${ }^{9}$ RAFT, ${ }^{10} \mathrm{NMP}^{4,11}$ ITP $^{12}$ and ATRP have been applied. Of all the CRPs, ATRP ${ }^{13}$ has been the focus of intense research in the polymer community owing to its versatility for the synthesis of well-defined polymers. Quite recently, Matyjaszewski's, ${ }^{14}$ Yagci's, ${ }^{15}$ and Hawker's ${ }^{16}$ groups have suc- 
cessfully devised reactive systems exploiting the redox properties of copper and iridium catalysts respectively in the presence of light. In this field, the development of very efficient photosensitive systems for UVA/visible light remains a huge challenge. Indeed, these types of radiation are safer than the more-energetic UVB and UVC light for the operator, more chemoselective causing less side reactions with reactants, and also eco-friendly (low energy consumption, no release of ozone or harmful UV rays and very little heat emission). Among the few examples of gold catalyzed polymerization, ${ }^{17}$ the use of a gold photocatalyst to promote photo-ATRP upon UVA/visible light has not been reported so far.

In this context, we showed that photoactivated digold bis (diphenylphosphino)methane dichloride $\left[\mathrm{Au}_{2}(\mu-\mathrm{dppm})_{2}\right] \mathrm{Cl}_{2} \quad \mathbf{1}$ first reported by Schmidbaur, ${ }^{18}$ was able to catalyze ATRP processes (Scheme 1). Photoredox properties of the corresponding photoactivated cationic complex $\left[\mathrm{Au}_{2}(\mu-\mathrm{dppm})_{2}\right]\left[\mathrm{ClO}_{4}\right]$ were studied by Che who highlighted its ability to generate carboncentered radicals by single electron transfer (SET) from alkyl halides. ${ }^{19}$ In 2013, Barriault nicely demonstrated the synthetic potential of $\mathbf{1}$ in combination with Hünig’s base as a sacrificial electron donor for the photoreduction of unactivated aryl and alkyl bromides. ${ }^{20}$ Inspired by these seminal studies, we anticipated that the unique properties of $\mathbf{1}$ would permit SET reduction of activated alkyl bromides, initiate and control ATRP processes. Therefore, we investigated the catalytic properties of $\mathbf{1}$ in different solvents at rt under light activation to generate a carbon-centered radical from ethyl $\alpha$-bromophenylacetate (EBPA, 2) and trigger polymerization of rather hydrophilic monomers such as methyl methacrylate (MMA, 3) in solution and trimethylolpropane triacrylate (TMPTA, 5) in laminate. Chain extension experiments with benzyl methacrylate (BnMA, 4) and hydrophobic 2,2,3,3,4,4,4-heptafluorobutyl acrylate (HFBA, 6) were also studied (Scheme 1).

$$
\begin{aligned}
& \mathrm{Ph}_{2} \mathrm{P}>\mathrm{PPh}_{2} \text { 1, }\left[\mathrm{Au}_{2}(\mathrm{dppm})_{2}\right] \mathrm{Cl}_{2}: \lambda_{\max }=295 \mathrm{~nm} \\
& \mathrm{Cl}-\mathrm{Au}^{\prime}-\mathrm{Au}^{-\mathrm{Cl}} \mathrm{E}^{\circ}\left(\mathrm{Au}_{2}{ }^{3+} / \mathrm{Au}_{2}{ }^{2+}\right)=-1.6 \mathrm{~V} \text { (SSCE in MeCN for } \mathrm{ClO}_{4}{ }^{-} \text {) } \\
& \mathrm{Ph}_{2} \mathrm{P} \smile \mathrm{PPh}_{2}
\end{aligned}
$$

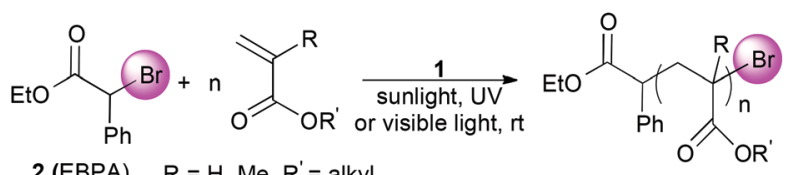$$
2 \text { (EBPA) } \quad \mathrm{R}=\mathrm{H}, \mathrm{Me}, \mathrm{R}^{\prime}=\text { alkyl }
$$

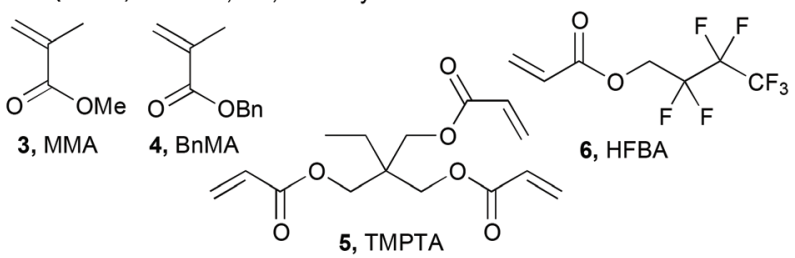

Scheme 1 Atom transfer radical polymerization of various (meth)acrylates catalyzed by digold bis(diphenylphosphino)methane dichloride $\left[\mathrm{Au}_{2}(\mu-\mathrm{dppm})_{2}\right] \mathrm{Cl}_{2} 1$ as a photoredox catalyst.

\section{Results and discussion}

UV-visible and luminescence spectroscopies were used to determine the photophysical properties of $\mathbf{1}$ and understand its role as a photoredox catalyst (see the ESI, S-8†). The UV-visible absorption spectrum of 1 exhibits two bands at $258 \mathrm{~nm}\left(\varepsilon_{\max }\right.$ $\left.42343 \mathrm{~L} \mathrm{~mol}^{-1} \mathrm{~cm}^{-1}\right)$ and $320 \mathrm{~nm}\left(\varepsilon_{\max } 11343 \mathrm{~L} \mathrm{~mol}^{-1} \mathrm{~cm}^{-1}\right)$. A weak and broad absorption band at $320 \mathrm{~nm}$ was visualized while under excitation at the same wavelength, the luminescence spectroscopy of $\mathbf{1}$ showed a strong emission-band at $390 \mathrm{~nm}$. Thus, the energy of the excited state has been determined as ${ }^{*} E\left(\mathrm{Au}_{2}^{\mathrm{II}}\right) \approx 3.5 \mathrm{eV}\left({ }^{*} E\left(\mathrm{Au}_{2}^{\mathrm{II}}\right) \approx 1240 /((390+320) / 2) \approx\right.$ $3.5 \mathrm{eV})$. The frontier molecular orbitals obtained for the optimized geometry of $\mathbf{1}$ are given in the ESI (Fig. $12 \dagger$ ) and suggest a metal to ligand charge transfer transition MLCT for this lowest energy band, the HOMO and the LUMO being located on the metal and ligand moieties, respectively.

We used laser flash photolysis (LFP) experiments in order to know if the initiator 2 was able to interact with the excited state of complex $\mathbf{1}\left(\mathrm{Au}_{2}^{\mathrm{II}}\right)$. The transient absorption spectrum was recorded after laser flash excitation at $355 \mathrm{~nm} .^{21}$ The excited state of $\mathbf{1}$ is characterized by a transient absorption at about $390 \mathrm{~nm}$ in accordance with Che's results. ${ }^{22}$ Then, LFP allowed the determination of the rate constant of the $\mathrm{Au}_{2}^{\mathrm{II}}{ }^{*}$ quenching by 2 (Fig. 1). ${ }^{23}$ An increasing amount of 2 was added to a solution of $\mathbf{1}$ under irradiation and a decay of $\mathrm{Au}_{2}^{\mathrm{II}}$ absorption at $390 \mathrm{~nm}$ in DCM was observed. When 2 was omitted, the lifetime of 1 was $1.56 \mu$ s under a nitrogen atmosphere. This value significantly decreased to $110 \mathrm{~ns}$ in the presence of $4 \mu \mathrm{L}$ of $2\left(7.6 \times 10^{-3} \mathrm{M}\right)$ (Fig. 1). From a Stern-Volmer analysis, we have found that 2 is an excellent oxidative quencher of $\mathrm{Au}_{2}^{\mathrm{II}^{*}}$ with a rate constant photolysis of $9.2 \times 10^{8}$ $\mathrm{M}^{-1} \mathrm{~s}^{-1}$. In addition, the cyclic voltammogram (CV) of 1 revealed three oxidation waves that appeared at $+0.6 \mathrm{~V},+1.2 \mathrm{~V}$ and $+2.0 \mathrm{~V}$ in MeCN vs. SCE. The first wave at $+0.6 \mathrm{~V}$ is assigned to the $\mathrm{Au}^{\mathrm{I}}$ metal-centered oxidation process while the $\mathrm{CV}$ of 2 also gave a reduction potential at $-1.3 \mathrm{~V}$ (in MeCN $v s$. SCE). Thus, the oxidation of $\mathrm{Au}_{2}^{\mathrm{II}^{*}}$ by 2 would presumably occur as supported by the favorable free energy change $\Delta G$,

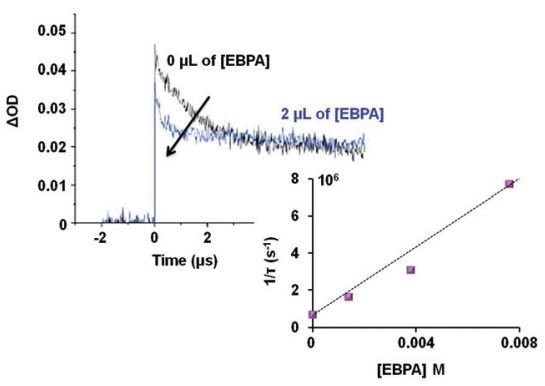

Fig. 1 Laser flash photolysis. Decay of the [1] $]^{1 / *}$ signal at $390 \mathrm{~nm}$ in dichloromethane with increasing concentrations of 2 . The arrow shows that the $\mathrm{Au}_{2}^{l \mid *}$ lifetime decreases as the concentration of $\mathbf{2}$ increases (from 0 to $7.6 \times 10^{-3} \mathrm{M}$ ). $\triangle O D$ is the change in optical density associated with the light excitation $(\lambda=355 \mathrm{~nm})$. 


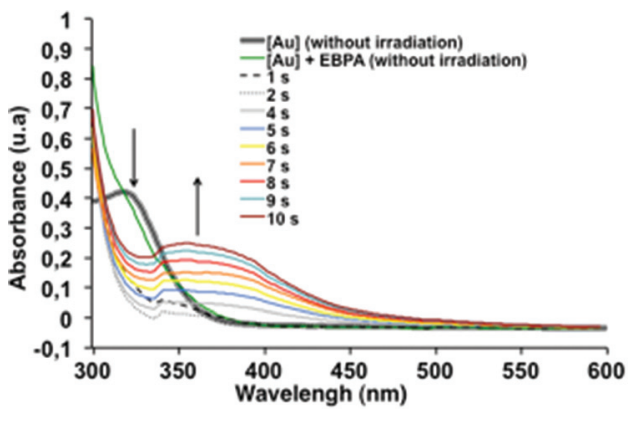

Fig. 2 Steady state photolysis of 1 and 2 in dichloromethane upon exposure to the $\mathrm{Xe}-\mathrm{Hg}$ under air at different irradiation times (from $t=$ 0 to $10 \mathrm{~s}$ ). 1/2: 1/0.045. UV-vis spectra clearly demonstrate that one species disappears rapidly at a very early stage and one appears.

derived from the Rehm-Weller equation $\left(\Delta G^{\circ}=-1.6 \mathrm{eV}\right)$ (see the ESI, S-10 $\dagger$ ). These initial findings suggest that the rate of photoreaction is primarily governed by the homolysis of the $\mathrm{C}$ $\mathrm{Br}$ bond of EBPA. These also support that the system $1 / 2$ could be used to initiate radical polymerization with no need of an additional sacrificial donor of electron, as required for the photoreduction of unactivated aryl and alkyl bromides. ${ }^{20}$

To support this mechanism, we monitored the steady state photolysis of [1] in the presence of 2 . We observed a strong decrease of the absorption band at $320 \mathrm{~nm}$ upon diode laser exposure concomitantly with the appearance of a band at $420 \mathrm{~nm}$ over $10 \mathrm{~s}$ of irradiation (Fig. 2). This result confirmed the quenching of the excited state of $\mathbf{1}$ by the initiator 2 leading to the formation of an ethyl phenylacetyl radical, that could initiate the radical polymerization, and an oxidized gold complex $\left\{\left[\mathrm{Au}_{2}(\mu-\mathrm{dppm})_{2} \mathrm{Cl}_{2}\right]^{+}, \mathrm{Br}^{-}\right\}$with an absorption UV signal suspected at $420 \mathrm{~nm}$.

From this system, the generation of a carbon-centered radical intermediate derived from 2 was also confirmed by ESR spin-trapping experiments (Fig. 3). ${ }^{24}$ A dichloromethane solution of $2 / 1$ and $N$-tert-butyl- $\alpha$-phenylnitrone (PBN) was irra-

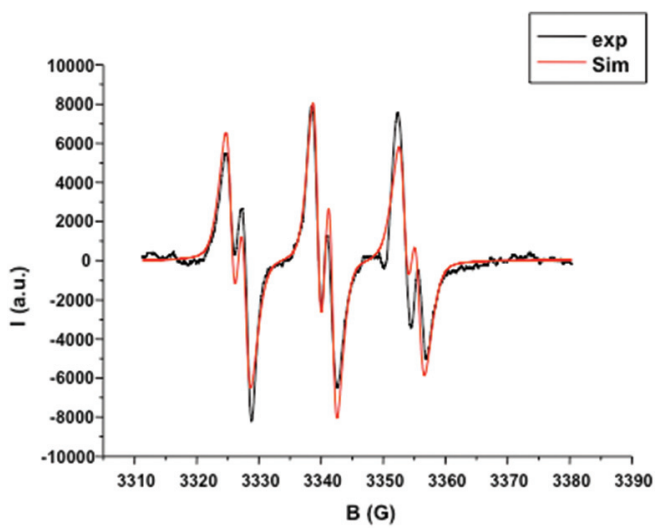

Fig. 3 ESR spin trapping (PBN) spectrum. $[\mathrm{PBN}]=7.90 \times 10^{-4} \mathrm{M}$, [1] = $1.57 \times 10^{-4} \mathrm{M}$, [2] = $1.91 \times 10^{-3} \mathrm{M}$ in $1.5 \mathrm{~mL}$ of DCM/tert-butylbenzene $1: 2$. diated (Xe-Hg lamp) for $20 \mathrm{~s}$ and monitored by ESR. A characteristic signal of a nitroxide adduct which originates from the addition of the phenylacetate radical to PBN $\left(a_{\mathrm{N}}=\right.$ 14.3 G, $a_{\mathrm{H}}=2.5 \mathrm{G}$ ) was observed. Similarly, 6 minutes of sunlight exposure to the same solution resulted in an identical ESR signal. This set of experiments confirmed that gold catalyst 1 allows a very responsive photo radical process and 2 is an excellent oxidative quencher. Given the perfect adequacy in terms of photochemical properties and reactivity between catalyst 1 and initiator 2, polymerization of MMA 3 in solution was then carried out.

The influence of the irradiation wavelength and the solvent was first examined. Typical conditions involved a controlled concentration of MMA (2.08 M) with an initiator/monomer/ catalyst $(2 / 3 / 1)$ ratio fixed at $1 / 500 / 0.0125(\mathrm{~mol} / \mathrm{mol})$. Conversion of 3 , molecular weight and dispersity of the so-formed PMMA were measured by gravimetry and GPC analysis and reported in Table 1.

Experiments were performed in $N, N^{\prime}$-dimethylformamide (DMF) or dichloromethane (DCM) under UV to visible-light activation at $25{ }^{\circ} \mathrm{C}$. At $300 \mathrm{~nm}$ in DMF, 84\% of conversion was reached in $24 \mathrm{~h}$ (Table 1, entry 1). PMMA with lower numberaverage molar mass than the theoretical value was obtained with a dispersity of 1.81 . Under these reaction conditions, effective initiation proceeded but the physical data of the PMMA can be indicative of side reactions. Lower conversions were observed at 380 and $419 \mathrm{~nm}$ (54 and 63\% respectively) and the resulting polymers have higher molar mass, revealing a failure of the initiation system (Table 1, entries 3 and 4). A good control of the polymerization was achieved when the irradiation was done at $350 \mathrm{~nm}$ (Table 1, entry 2). The conversion of MMA was $75 \%$, the molar mass distribution $(\nexists)$ of

Table 1 Polymerization of MMA 3 catalyzed by $\left[\mathrm{Au}_{2}(\mu-\mathrm{dppm})_{2}\right] \mathrm{Cl}_{2}$ under light activation ${ }^{a}$

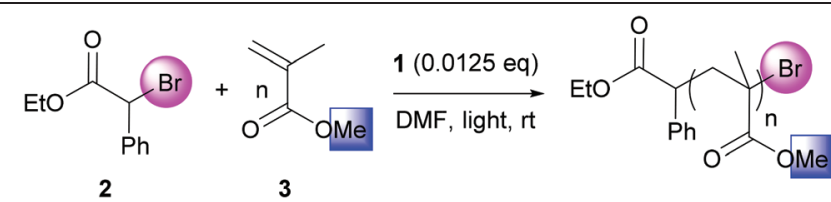

\begin{tabular}{llllll}
\hline Entry & $\begin{array}{l}\text { Light } \\
(\mathrm{nm})\end{array}$ & $\begin{array}{l}2 \mathrm{Conv} .^{b} \\
(\%)\end{array}$ & $\begin{array}{l}M_{\mathrm{n}, \text { theo }} \\
\left.(\mathrm{kg} \mathrm{mol})^{-1}\right)\end{array}$ & $\begin{array}{l}M_{\mathrm{n}, \exp } \\
\left(\mathrm{kg} \mathrm{mol}^{-1}\right)\end{array}$ & $\Xi^{c}$ \\
\hline 1 & 300 & 84 & 42.3 & 34.0 & 1.81 \\
2 & 350 & 75 & 37.5 & 34.0 & 1.67 \\
3 & 380 & 54 & 27.4 & 42.0 & 1.77 \\
4 & 419 & 63 & 31.7 & 48.4 & 1.85 \\
5 & $350^{d}$ & 55 & 27.8 & 24.7 & 1.62 \\
6 & Dark & - & - & - & - \\
7 & $350^{e}$ & 100 & 50.0 & 25.0 & 2.1
\end{tabular}

${ }^{a}$ Polymerizations were performed with $[\mathrm{MMA}]=2.08 \mathrm{M}$ (vol MMA + vol solvent) at rt with $2 / 3 / 1=1 / 500 / 0.0125 \mathrm{~mol} / \mathrm{mol}$. All reactions were degassed before setting the reaction. ${ }^{b}$ Conversion measured by gravimetric analysis. ${ }^{c}$ Determined after one precipitation in $\mathrm{MeOH}$. ${ }^{g}$ Reaction performed in DCM. ${ }^{e}$ Reaction in a mixture $2 / 3$ (1/500) in DMF without the gold catalyst. 
PMMA decreased to 1.67 with a number-average molar mass closer than the theoretical value. Well controlled polymerization was also obtained in DCM under irradiation at $350 \mathrm{~nm}$ (Table 1, entry 5). Molar mass fitted with the theoretical value and the dispersity was 1.62 . These last results indicated that the initiation process was efficient and side reactions giving birth to dead chains were very limited. In order to argue in the favor of a controlled radical polymerization, the same mixture of 2/3/1 was placed in the dark and no polymer was formed (Table 1, entry 6). If the gold catalyst was omitted, polymerization occurred but it could not be controlled (Table 1, entry 7 ).

To evaluate the living character of this polymerization process, chain extension experiments were conducted using MMA or BnMA as the second monomer (Scheme 2). An original sample of PMMA obtained by the present protocol and purified by precipitation in methanol $\left(M_{\mathrm{n}}=18.0 \mathrm{~kg} \mathrm{~mol}^{-1}, D=\right.$ 1.32), was considered as a macroinitiator and placed in DMF with MMA 3 and the gold photocatalyst 1 in a 1/500/0.0125 proportion respectively (Scheme $2 \mathrm{~A}$ ). After $24 \mathrm{~h}$ of irradiation at $350 \mathrm{~nm}$, a PMMA homopolymer was isolated showing an important increase of $M_{\mathrm{n}}$ up to $30.9 \mathrm{~kg} \mathrm{~mol}{ }^{-1}$. From a different PMMA sample $\left(M_{\mathrm{n}, \exp }=14.2 \mathrm{~kg} \mathrm{~mol}^{-1}, Ð=1.50\right)$, a block copolymer was obtained with BnMA 4 (PMMA/4/1 1/500/0.0125 mol/ mol) (Scheme 2B). Similarly, a considerable $M_{\mathrm{n}, \exp }$ increase was
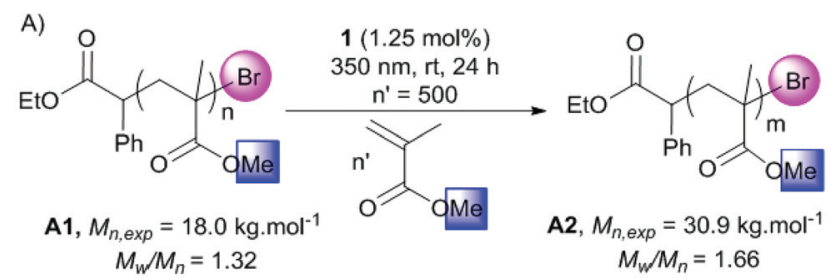

A2, $M_{n, \exp }=30.9 \mathrm{~kg} \cdot \mathrm{mol}^{-1}$ $M_{w} / M_{n}=1.66$<smiles>CCOC(=O)C([18O])([18OH])c1ccccc1</smiles>
$1(1.25 \mathrm{~mol} \%)$
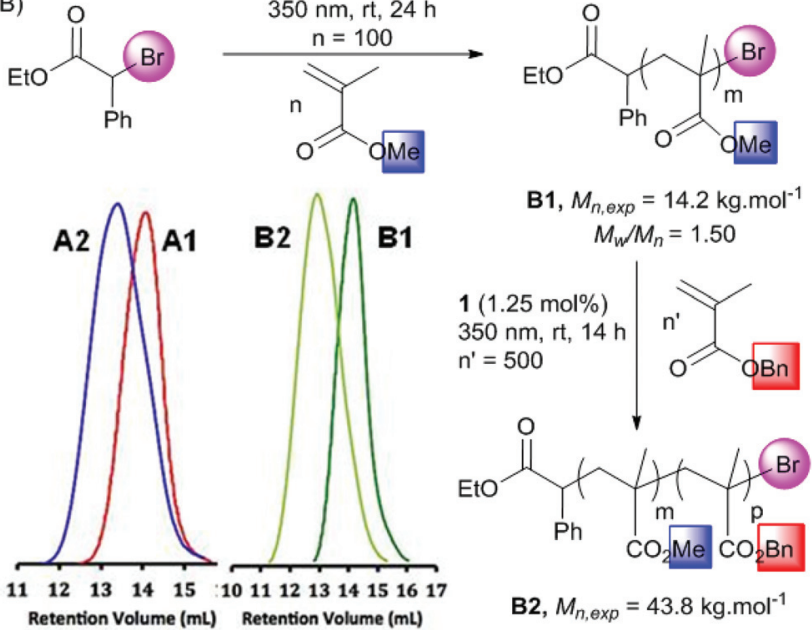

B2, $M_{n, \exp }=43.8 \mathrm{~kg} \cdot \mathrm{mol}^{-1}$ $M_{w} / M_{n}=1.80$
Scheme 2 (A) Chain extension of poly(methyl methacrylate) with MMA and SEC chromatogram with the red and blue traces corresponding respectively to $A 1$ and $A 2$. (B) Synthesis of poly(methyl methacrylate)- $b$ poly(benzyl methacrylate) well defined diblock copolymer and dark green and light green SEC chromatograms corresponding respectively to $\mathrm{B} 1$ and $\mathrm{B} 2$.

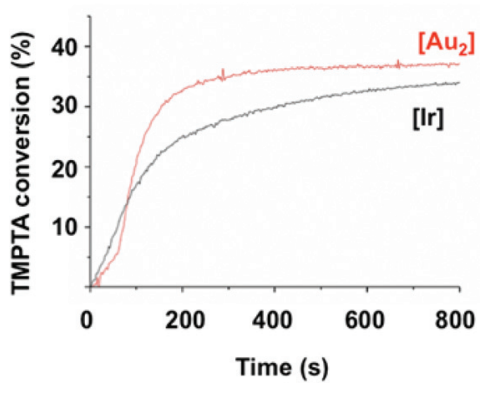

Fig. 4 Compared polymerization profiles for TMPTA in the laminate system for different catalysts upon a blue LED bulb irradiation (405 nm). Red curve: 2/5/1 (1/100/0.0125 mol/mol); black curve: 2/5/fac- $\operatorname{lr}($ ppy) 3 $(1 / 100 / 0.0125 \mathrm{~mol} / \mathrm{mol})$.

observed and has been determined to be $43.8 \mathrm{~kg} \mathrm{~mol}^{-1}$. The corresponding SEC traces of both experiments showed the evolution of the polymer populations. This clearly demonstrated the possibility of reactivating the bromide terminus of the polymer. Thus, it appears reasonable to postulate a photoATRP pathway for this novel new gold-catalyzed polymerization.

As initial experiments revealed that 1 efficiently catalyzes the polymerization of methacrylates $\mathbf{3}$ and $\mathbf{4}$ in solution, comparative kinetic experiments were carried out. A laminate system was chosen to compare the present system (2/1) with

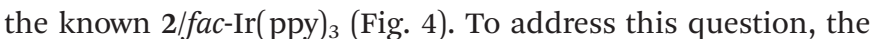
polymerization of TMPTA 5 in laminate with both systems was monitored by RT-FTIR spectroscopy at $405 \mathrm{~nm}$. The disappearance of a characteristic absorption band of $5\left(1600-1650 \mathrm{~cm}^{-1}\right)$ served to measure the conversion of this monomer. ${ }^{25}$ The $2 /$ fac-Ir(ppy) $)_{3}$ polymerization profile (black curve) showed a rapid initial rate to reach $33 \%$ conversion in 800 s. After an activation period of $50 \mathrm{~s}$, the $\mathbf{2} / \mathbf{1}$ system gave a faster polymerization rate than with iridium to reach $38 \%$ conversion in $400 \mathrm{~s}$. The iridium catalyst was already known to be very efficient but to our delight, this new gold photocatalyst 1 proved to be even more active for the polymerization of acrylates in bulk.

The dependence of this polymerization process on light was further studied by employing a periodic "on/off" light event during the TMPTA polymerization in laminate 2/5/1 (1/ 100/0.0125 mol/mol) (Fig. 5). The film was irradiated with LED

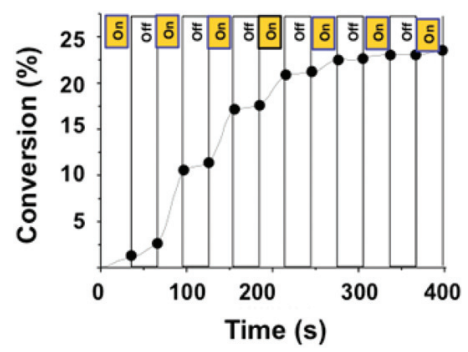

Fig. 5 TMPTA conversion as a function of time for intermittent blue LED bulb irradiation. Polymerization was performed from a 2/5/1 (1/100/ $0.0125 \mathrm{~mol} / \mathrm{mol}$ ) mixture. 
bulbs (405 $\mathrm{nm}$ ) with alternating irradiation periods (30 s) and blackout (30 s). The conversion of 5 was monitored by RT-FTIR spectroscopy and is reported in Fig. 5 according to the sequential irradiation. The polymerization rates were dramatically impacted and turning off the light resulted in a significantly low rate. Thus, a clear acceleration of the polymerization was observed under irradiation. This experiment also showed the living character of the polymerization and turning off the light did not induce the interruption of the growing chains.

An investigation of the living character was extended to surface functionalization. PhotoATRP of TMPTA 5 in laminate with the $2 / 1$ system (2/5/1 1/100/0.0125 $\mathrm{mol} / \mathrm{mol})$ allowed obtaining a well defined film after $\mathrm{Xe}-\mathrm{Hg}$ lamp irradiation for 3 min (Fig. 6A). The residual monomer was removed by washing with acetone and the surface was analyzed by XPS (see the ESI $\dagger$ for the full spectrum). This analysis evidenced the presence of gold and bromine atoms at the surface of the film. A drop of water on the layer made a $55^{\circ}$ contact angle in agreement with the wettability character of PMMA. Then, HFBA 6 was deposited on the surface of the first layer and irradiated under the same conditions for 10 minutes (Fig. 6B). The contact angle dramatically changed from $55^{\circ}$ to $115^{\circ}$, illustrating the surface modification to a more hydrophobic property due to the presence of perfluoroalkyl chains. This change proved the reactivation of the first layer for the synthesis of a block copolymer. Moreover, XPS of the second layer still showed the presence of gold and bromine atoms and opened the possibility of a third reactivation process (Fig. 6C). TEM (Transmission Electron Microscopy) analysis allowed visualization of the layer surfaces and so helped to exclude the presence of gold nanoparticles which could have been the active catalyst.

All these experiments completed by further mass spectrometry analysis by MALDI-TOF/ESI-TOF and ATRA studies (see the ESI, S17 and S18†) drove us to the following mechanism proposal for this new photoATRP process (Scheme 3). The polymerization relies on the in situ photogeneration of excited state $[\mathbf{1}]^{*}$ and its subsequent reaction with alkyl halide $\left(\mathrm{P}_{n}-\mathrm{X}\right)$ resulting in the formation of the active radical $\left(\mathrm{P}_{n}{ }^{\circ}\right)$ and $\left[\mathrm{Au}_{2}\right]^{\mathrm{III} X} \mathrm{X}$. Then, the radical adds onto a monomer and the resulting radical is rapidly deactivated by $\left[\mathrm{Au}_{2}\right]^{\mathrm{III}} \mathrm{X}$ to form a dormant species and regenerate $\mathbf{1}$.

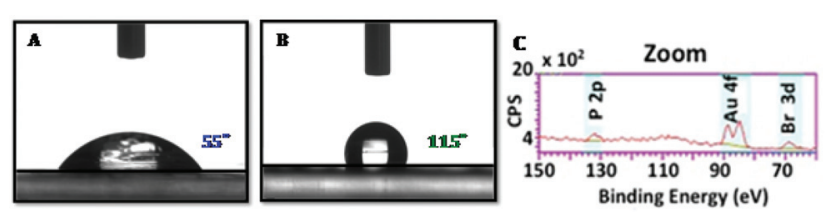

Fig. 6 Contact angle experiments: (Picture A) first layer: TPMTA/[Au $\left.{ }_{2}\right] /$ EBPA: $100 / 0.0125 / 1 \mathrm{~mol} / \mathrm{mol}$ after 3 minutes upon a blue LED bulb irradiation $(405 \mathrm{~nm})$. (Picture B) second layer after re-initiation with a fluoromonomer (HFBA 6) after 10 minutes upon a Xe-Hg lamp. (Picture C) represents high resolution XPS spectra after re-initiation and formation of the fluorinated polymer.

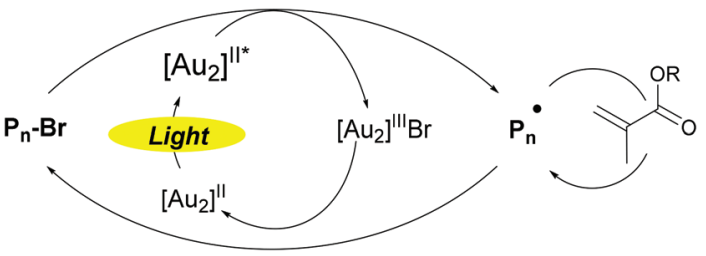

Scheme 3 Proposed mechanism for photoATRP of (meth)acrylates using $\left[\mathrm{Au}_{2}(\mu-\mathrm{dppm})_{2}\right] \mathrm{Cl}_{2}$ as a photocatalyst.

\section{Conclusions}

In summary, we report here the first gold-catalyzed photoATRP process of methacrylates and acrylates. The novel photocatalyst $\left[\mathrm{Au}_{2}(\mu-\mathrm{dppm})_{2}\right] \mathrm{Cl}_{2}$ in combination with ethyl $\alpha$-bromophenylacetate (EBPA) as the initiator allows the development of a highly responsive controlled living radical polymerization under UVA, sunlight and visible-light irradiation conditions as evidenced by fluorescence and absorbance measurements, steady-state photolysis, laser flash photolysis (LFP), electron spin resonance (ESR) experiments, Fourier transform infrared (FTIR) spectroscopy and "on-off" switchable experiments. In solution, the linear increase of molecular weights with methyl methacrylate (MMA) conversion and the low dispersity are consistent with a controlled/living process. In the film, trimethylolpropane triacrylate (TMPTA) was polymerized and the ethyl $\alpha$-bromophenylacetate $\quad(\mathrm{EBPA}) /\left[\mathrm{Au}_{2}(\mu-\mathrm{dppm})_{2}\right] \mathrm{Cl}_{2} \quad$ system resulted in a faster rate of polymerization compared to EBPA/ $\operatorname{Ir}(\mathrm{ppy})_{3}$. Chain extensions of polymers were successfully conducted leading to block copolymers, which confirmed the living character of this system. Importantly, this approach utilizes a gold catalyst with lower cost and more soluble than conventional iridium complexes. The use of dichloromethane as the solvent without loss of reactivity will open new perspectives in the combination of this photoATRP process with other polymerization modes. Moreover, the reported system is highly sensitive to sunlight and application of photopolymerization using this source of energy will be envisaged.

\section{Acknowledgements}

This work was supported by the CNRS, UPMC and IUF, which we gratefully acknowledge. This work was supported by the LabEx MiChem part of French state funds managed by the ANR within the Investissements d'Avenir programme under reference ANR-11-IDEX-0004-02. JPG thanks UHA, Fondation pour l'ENSCMu and Actelion for support (Actelion Chair in Innovative Organic Chemistry). The authors acknowledge ANR (NHCX ANR-11-BS07-008) for stimulating fruitful collaborations. 


\section{Notes and references}

1 (a) W. A. Braunecker and K. Matyjaszewski, Prog. Polym. Sci., 2007, 32, 93; (b) A. Goto and T. Fukuda, Prog. Polym. Sci., 2004, 29, 329.

2 (a) C. Boyer, V. Bulmus, T. P. Davis, V. Ladmiral, J. Liu and S. Perrier, Chem. Rev., 2009, 109, 5402; (b) J. Chiefari, Y. K. Chong, F. Ercole, J. Krstina, J. Jeffery, T. P. T. Le, R. T. A. Mayadunne, G. F. Meijs, C. L. Moad, G. Moad, E. Rizzardo and S. H. Thang, Macromolecules, 1998, 31, 5559.

3 (a) I. Allaoua, B. E. Goi, M. M. Obadia, A. Debuigne, C. Detrembleur and E. Drockenmuller, Polym. Chem., 2014, 5, 2973; (b) L. E. N. Allan, M. R. Perry and M. P. Shaver, Prog. Polym. Sci., 2012, 37, 127; (c) S. Yamago, Chem. Rev., 2009, 109, 5051.

4 (a) J. Nicolas, Y. Guillaneuf, C. Lefay, D. Bertin, D. Gigmes and B. Charleux, Prog. Polym. Sci., 2013, 38, 63; (b) C. J. Hawker, A. W. Bosman and E. Harth, Chem. Rev., 2001, 101, 3661.

5 (a) J. S. Wang and K. Matyjaszewski, J. Am. Chem. Soc., 1995, 117, 5614; (b) M. Kato, M. Kamigaito, M. Sawamoto and T. Higashimura, Macromolecules, 1995, 28, 1721; (c) T. E. Patten, J. Xia, T. Abernathy and K. Matyjaszewski, Science, 1996, 272, 866; (d) K. Matyjaszewski and J. Xia, Chem. Rev., 2001, 101, 2921; (e) K. Matyjaszewski and N. V. Tsarevsky, J. Am. Chem. Soc., 2014, 136, 6513.

6 (a) F. A. Leibfarth, K. M. Mattson, B. P. Fors, H. A. Collins and C. J. Hawker, Angew. Chem., Int. Ed., 2013, 52, 199; (b) Y. Yagci, S. Jockusch and N. J. Turro, Macromolecules, 2010, 43, 6245; (c) N. J. Treat, H. Sprafke, J. W. Kramer, P. G. Clark, B. E. Barton, J. R. de Alaniz, B. P. Fors and C. J. Hawker, J. Am. Chem. Soc., 2014, 136, 16096.

7 For reviews on photoredox catalysis in organic synthesis, see: (a) C. K. Prier, D. A. Rankic and D. W. C. MacMillan, Chem. Rev., 2013, 113, 5322; (b) J. M. R. Narayanam and C. R. J. Stephenson, Chem. Soc. Rev., 2010, 40, 102; (c) T. P. Yoon, M. A. Ischay and J. Du, Nat. Chem., 2010, 2, 527. For our contributions to this field, see: (d) M. H. Larraufie, R. Pellet, L. Fensterbank, J.-P. Goddard, E. Lacôte, M. Malacria and C. Ollivier, Angew. Chem., Int. Ed., 2011, 50, 4463; (e) S. Donck, A. Baroudi, L. Fensterbank, J.-P. Goddard and C. Ollivier, Adv. Synth. Catal., 2013, 355, 1477; (f) A. Baralle, L. Fensterbank, J.-P. Goddard and C. Ollivier, Chem. - Eur. J., 2013, 19, 10809; ( $g$ ) M. Daniel, L. Fensterbank, J.-P. Goddard and C. Ollivier, Org. Chem. Front., 2014, 1, 551; (h) L. Chenneberg, A. Baralle, M. Daniel, L. Fensterbank, J.-P. Goddard and C. Ollivier, Adv. Synth. Catal., 2014, 356, 2756.

8 T. Otsu and A. Kuriyama, Polym. J., 1985, 17, 97.

9 (a) S. Yamago, Y. Ukai, A. Matsumoto and Y. Nakamura, J. Am. Chem. Soc., 2009, 131, 2100; (b) A. Nomura, A. Goto, K. Ohno, E. Kayahara, S. Yamago and Y. Tsujii, J. Polym. Sci., Part A: Polym. Chem., 2011, 49, 5284; (c) C. Detrembleur, D.-L. Versace, Y. Piette, M. Hurtgen,
C. Jérôme, J. Lalevée and A. Debuigne, Polym. Chem., 2012, 3, 1856; (d) Y. Nakamura, T. Arima, S. Tomita and S. Yamago, J. Am. Chem. Soc., 2012, 134, 5536; (e) Y. Nakamura and S. Yamago, Beilstein J. Org. Chem., 2013, 9, 1607.

10 (a) J. F. Quinn, L. Barner, C. Barner-Kowollik, E. Rizzardo and T. P. Davis, Macromolecules, 2002, 35, 7620; (b) S. Muthukrishnan, E. H. Pan, M. H. Stenzel, C. BarnerKowollik, T. P. Davis, D. Lewis and L. Barner, Macromolecules, 2007, 40, 2978; (c) M. A. Tasdelen, Y. Y. Durmaz, B. Karagoz, N. Bicak and Y. Yagci, J. Polym. Sci., Part A: Polym. Chem., 2008, 46, 3387; (d) C. Zhang, Y. Yang and J. He, Macromolecules, 2013, 46, 3985; (e) J. Xu, K. Jung, A. Atme, S. Shanmugam and C. Boyer, J. Am. Chem. Soc., 2014, 136, 5508.

11 (a) S. Hu, J. H. Malpert, X. Yang and D. C. Neckers, Polymer, 2000, 41, 445; (b) Y. Guillaneuf, D.-L. Versace, D. Bertin, J. Lalevée, D. Gigmes and J. P. Fouassier, Macromol. Rapid Commun., 2010, 31, 1909; (c) D.-L. Versace, J. Lalevée, J. P. Fouassier, D. Gigmes, Y. Guillaneuf and D. Bertin, J. Polym. Sci., Part A: Polym. Chem., 2010, 48, 2910; (d) D.-L. Versace, J. Lalevée, J. P. Fouassier, Y. Guillaneuf, D. Bertin and D. Gigmes, Macromol. Rapid Commun., 2010, 31, 1383; (e) Y. Guillaneuf, D. Bertin, D. Gigmes, D.-L. Versace, J. Lalevée and J. P. Fouassier, Macromolecules, 2010, 43, 2204.

12 A. Wolpers and P. Vana, Macromolecules, 2014, 47, 954.

13 (a) Z. Guan and B. Smart, Macromolecules, 2000, 33, 6904; (b) J. Mosnáček and M. Ilčíková, Macromolecules, 2012, 45, 5859; (c) N. V. Alfredo, N. E. Jalapa, S. L. Morales, A. D. Ryabov, R. Le Lagadec and L. Alexandrova, Macromolecules, 2012, 45, 8135.

14 (a) Y. Kwak and K. Matyjaszewski, Macromolecules, 2010, 43, 5180; (b) D. Konkolewicz, K. Schröder, J. Buback, S. Bernhard and K. Matyjaszewski, ACS Macro Lett., 2012, 1, 1219.

15 (a) M. A. Tasdelen, M. Uygun and Y. Yagci, Macromol. Rapid Commun., 2011, 32, 58; (b) M. A. Tasdelen, M. Ciftci and Y. Yagci, Macromol. Chem. Phys., 2012, 213, 1391.

16 (a) B. P. Fors and C. J. Hawker, Angew. Chem., Int. Ed., 2012, 51, 8850; (b) N. J. Treat, B. P. Fors, J. W. Kramer, M. Christianson, C.-Y. Chiu, J. R. de Alaniz and C. J. Hawker, ACS Macro Lett., 2014, 3, 580.

17 (a) L. Ray, V. Katiyar, M. J. Raihan, H. Nanavati, M. M. Shaikh and P. Ghosh, Eur. J. Inorg. Chem., 2006, 3724; (b) L. Ray, V. Katiyar, S. Barman, M. J. Raihan, H. Nanavati, M. M. Shaikh and P. Ghosh, J. Organomet. Chem., 2007, 692, 4259; (c) J. Urbano, A. J. Hormigo, P. de Frémont, S. P. Nolan, M. M. Díaz-Requejo and P. J. Pérez, Chem. Commun., 2008, 759; (d) E. Brulé, S. Gaillard, M.-N. Rager, T. Roisnel, V. Guérineau, S. P. Nolan and C. M. Thomas, Organometallics, 2011, 30, 2650; (e) R. A. Sanguramath, S. K. Patra, M. Green and C. A. Russell, Chem. Commun., 2012, 48, 1060; (f) F. Nzulu, A. Bontemps, J. Robert, M. Barbazanges, L. Fensterbank, 
J.-P. Goddard, M. Malacria, C. Ollivier, M. Petit, J. Rieger and F. Stoffelbach, Macromolecules, 2014, 47, 6652.

18 H. Schmidbaur, A. Wohlleben, F. Wagner, O. Orama and G. Huttner, Eur. J. Inorg. Chem., 1977, 110, 1748.

19 (a) D. Li, C.-M. Che, H.-L. Kwong and V. W.-W. Yam, J. Chem. Soc., Dalton Trans., 1992, 3325; (b) C.-M. Che, H.-K. Yip, V. W.-W. Yam, P.-Y. Cheung, T.-F. Lai, S.-J. Shieh and S.-M. Peng, J. Chem. Soc., Dalton Trans., 1992, 427.

20 (a) G. Revol, T. McCallum, M. Morin, F. Gagosz and L. Barriault, Angew. Chem., Int. Ed., 2013, 52, 13342; (b) T. McCallum, E. Slavko, M. Morin and L. Barriault, Eur. J. Org. Chem., 2015, 81.

21 The wavelength $355 \mathrm{~nm}$ corresponds to the third Nd:YAG harmonic.

22 C.-M. Che, H.-L. Kwong and C.-K. Poonhieh, J. Chem. Soc., Dalton Trans., 1990, 3215.
23 (a) J. Lalevée, N. Blanchard, C. Fries, M.-A. Tehfe, F. MorletSavary and J. P. Fouassier, Polym. Chem., 2011, 2, 1077; (b) S. Telitel, J. Lalevée, N. Blanchard, T. Kavalli, M.-A. Tehfe, F. Morlet-Savary, B. Graff and J. P. Fouassier, Macromolecules, 2012, 45, 6864.

24 (a) N. M. Atherton, M. J. Davies, B. C. Gilbert and P. Tordo, in Spin-Trapping: Recent Developments and Applications, in Electron Paramagnetic Resonance: Volume 16, ed. B. C. Gilbert, N. M. Atherton and M. J. Davies, The Royal Society of Chemistry, Cambridge, U.K., 1998, vol. 16, p. 116; (b) J. Lalevée, F. Dumur, C. R. Mayer, D. Gigmes, G. Nasr, M. A. Tehfe, S. Telitel, F. Morlet-Savary, B. Graff and J. P. Fouassier, Macromolecules, 2012, 45, 4134.

25 S. Telitel, F. Dumur, S. Telitel, O. Soppera, M. Lepeltier, Y. Guillaneuf, J. Poly, F. Morlet-Savary, P. Fioux, J. P. Fouassier, D. Gigmes and J. Lalevée, Polym. Chem., $2015,6,613$. 